\section{Lessons from the Pandemic}

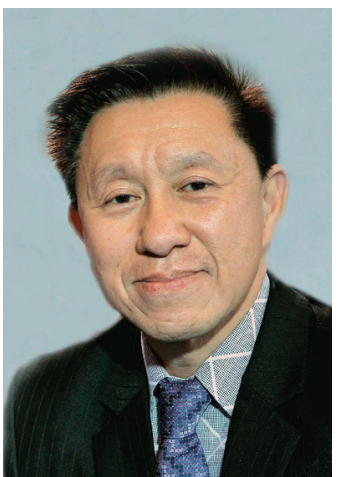

We have seen the events of the pandemic unfold from our unique perspective as pathologists. Early on, we stood helpless as the virus ravaged our cities and towns with ferocity while we could hardly do anything. We were woefully unprepared to cope with the testing. Very few labs were capable of doing RTPCR testing, exposing our unpreparedness in molecular pathology.

Now, we are empowered with the existence of over two hundred molecular labs that can be harnessed to combat the pandemic. Our once sleepy lives have been jolted into action by the urgency of identifying virus infections. Furthermore, the rampant spread of the virus has given rise to many variants, thus requiring much more testing than we are currently doing.

Almost as soon as the pandemic began last year, the Philippine Society of Pathologists Inc. (PSPI) produced position papers urging the use of pooled testing to expand testing capacity as a solution to the scarcity of reagents, PPE, and manpower, as well as a way to overcome cost constraints. We launched a study for proof of concept, resulting in the Department of Health's finally giving its imprimatur for its use on a national basis.' We held trainings for pooled testing to empower many labs to perform it, in the hope that it would further expand testing capacity. This, however, has remained constricted due to cost issues. ${ }^{2}$

Surveillance testing is very important, because asymptomatic persons are driving the spread in our population. If we do not identify and isolate these spreaders, we will continue to experience outbreaks and possibly more surges such as occurred early in the second quarter of 2021. Once again, the PSPI has proposed pooled testing as a means to curb localized outbreaks from which major surges may arise. ${ }^{2}$ Unfortunately, the authorities seem to have turned a deaf ear to our call despite its potential benefits: It would mean an easing of lockdowns and other economic restrictions if it were to be implemented on a widespread basis. It would control the cycle of surges and lockdowns as are happening now in various areas in the country.

Now, to the issues still vexing our pandemic response. The fragmented reactions of local governments are a main concern. The devolution of health care was fine in previous situations, but the public health emer- gency of a pandemic demands a more cohesive approach on a national level. This will have to be solved by our lawmakers.

As in many emergencies, quick thinking with reflex actions based on previous experience and practice will solve many problems. Mental agility, however, has not been a manifest virtue of our government agencies. This cannot be the norm in pandemics. We need to plan ahead while still grappling with the SARSCoV-2 pandemic, which we must presume is but a harbinger of things to come.

The proposed Philippine Centers for Disease Control (PCDC) will be a step in the right direction. Pathologists would be assigned as laboratory directors, while the rest can perform other functions in research, test development, and quality assurance. Hence, we can plan a more functional response if and when outbreaks, epidemics, and pandemics occur. It is we pathologists who are more acquainted with laboratory techniques and testing, so it is but right to have one at the helm. Make no mistake about it, we will have more pandemics. It is only a matter of time, now measured not in centuries as previously happened but more in decades or years.

The deficiencies we saw last year are the ones we should be addressing now. Capacity building for gene sequencing is fundamental to identifying new, emerging, and re-emerging viral and other infections capable of developing into pandemics. We cannot just rely on foreign agencies to identify a pathogen that has sprung in our midst.

The supply constraints we experienced are lessons to draw from so that we can respond more adequately and plan for a more secure supply chain not wholly dependent on foreign sources. We should develop our own molecular reagents, which should be validated and can be applied to these new pathogens in as quick a time period as possible.

Having identified and sequenced a new pathogen, we should be capable of developing our own testing kits with the various components we should have stocked up on previously. This-combined with the many molecular laboratories we now have and the validated pooled testing technique our Society has pioneered in-will prevent the huge backlog of testing we saw in the early months of last year. ${ }^{2}$

There will be questions as to the feasibility or viability of this scenario. Some may ask: What will this agency be doing while awaiting the next pandemic? Will the equipment become outdated, and reagents expire? 
Well, no. We should not just be waiting for the next pandemic. We can cut our teeth, so to speak, on proactively solving public health concerns rather than just reacting as our health system is currently doing.

This agency should be monitoring diseases of concern like TB, HIV, polio, measles, and other viral infections plaguing our country now. Using the lessons learned from this pandemic, we can track possible outbreaks with routine periodic testing of sewage for polio virus, and even for SARS-CoV-2. What better way for us to do this than with the economics of scale that pooled testing provides?2 ${ }^{2}$ The same technique can be used for other respiratory diseases that routinely visit the country.

Another object lesson is the impracticality of concentrating testing expertise in one or two institutions. This creates bottlenecks in combatting epidemics/ pandemics, as we saw last year. We should continue training laboratory personnel and managers, both public and private, in testing techniques that matter in public health emergencies. Let us regionalize our efforts in public health surveillance by capacitating major regional centers for disease control.

Lack of training has been another issue in our response to this pandemic. We have been remiss in the training of medical technologists for molecular testing, again because of centralization. Let us have more capacity building for training as well. With the continuous exodus of our health workers, including medical technologists, we have no recourse but to keep training them as soon as they enter the workforce.

Planning should include embracing new technology as it arises. Updating our diagnostic armamentarium should be top priority now and in the future. Faster, more efficient, and accurate equipment makes for a more agile response to a rapidly developing infectious-disease scenario. Needless to say, this requires making our government leaders aware of its importance and for them to regularly allot the correct fiscal budget on a regular and not just a one-time basis.
Research should play a major role in public health matters. How else will we know the insidious-creeping incidence of infectious diseases without top-notch medical sleuthing? These centers for disease control should also make budget provisions for research and reagent formulations.

In summary, we should learn from our mistakes committed during this pandemic, which has already caught us flat-footed. Let us start our capacity building by investing in our public health laboratories, equipping them properly, staffing them with trained competent people, continuously monitoring endemic and emerging diseases, and insuring supply-chain continuity in the face of rapidly emerging infectious diseases. It is a war we cannot afford to lose.

\section{Raymundo W. Lo, MD, FPSP}

Anatomic and Clinical Pathologist, Philippine Children's Medical Center

Quezon City, Philippines

\section{REFERENCES}

1. Padua R Jr. Diagnostic testing strategies to manage CoVID-19 pandemic: proposed by the Philippine Society of Pathologists, Inc. Philipp J Pathol. 2020;5(1):5-8. https://doi.org/10.21141/PJP.2020.08.

2. Lo RW, Barrientos A, Espiritu B, et al. An evaluation of pooling strategies for RT-qPCR testing for SARSCoV-2 infection: a pragmatic multi-site parallel operational study. Philipp J Pathol. 2020;5(2):12-33. https://doi.org/ 10.21141/PJP.2020.12.

Dr. Raymundo Lo is a respected pathologist and member of the Philippine Society of Pathologists, Inc., a columnist of the Manila Bulletin, an editorial board member of the Philippine Journal of Pathology, and a member of the COVID-19 Laboratory Experts Panel (CLEP) of the Department of Health.

https://doi.org/10.21141/PJP.2021.10 